\title{
Evolving therapeutic strategies for premature ejaculation: The search for on-demand treatment - topical versus systemic
}

\author{
Alvaro Morales, CM, MD, FRCSC, FACS \\ Queen's University, Kingston, ON
}

Cite as: Can Urol Assoc J 2012;6(5):380-5. htrp://dx.doi.org/10.5489/cuaj.12002

\begin{abstract}
Premature ejaculation (PE) is a common sexual dysfunction affecting $20 \%$ to $30 \%$ of men worldwide. Definitions of PE vary, but it is typically characterized by short intravaginal ejaculatory latency time (IELT) with concomitant sexual dissatisfaction and distress. PE may be lifelong or acquired, but its etiology remains unclear. Treatment of PE typically involves pharmacotherapy, particularly when lifelong. Although there are numerous reports on the offlabel use of selective serotonin reuptake inhibitors (SSRIs) and other compounds, only 2 treatments have been evaluated in randomized controlled phase 3 clinical trials: PSD502 and dapoxetine (SSRI). Both significantly improved IELT and patient-reported outcome domains of ejaculatory control, sexual satisfaction, and distress as measured by the index of premature ejaculation (IPE), compared with placebo. They constitute the focus of this review. Evidence demonstrated that PSD502, dapoxetine and other SSRIs all significantly improve the symptoms of PE. Systemic use of SSRIs presents risks associated with the known pharmacology of this class. PSD502 allows for topical on-demand treatment applied applied immediately before intercourse, and is not associated with systemic adverse events.
\end{abstract}

\section{Introduction}

Treatments for premature ejaculation (PE) aim at decreasing sensory input and behavioural modification. ${ }^{1,2}$ However, due to its incomplete definition and characterization, ${ }^{3,4} \mathrm{PE}$ remains underdiagnosed and undertreated..$^{5}$ There are no pharmacological therapies approved by the U.S. Food and Drug Administration (FDA) for $\mathrm{PE}$; therefore, treatment involves off-label use of selective serotonin reuptake inhibitors (SSRIs) or topical anesthetics., ${ }^{4,6}$ Dapoxetine is a short-acting SSRI that has been approved for use in PE in several European countries and in New Zealand, but not in North America. ${ }^{4,7}$ PSD502 is a topical formulation of lidocaine and prilocaine, which is in the later stages of clinical development. This review examines on-demand therapies and compares them with systemic agents administered on a daily basis.

\section{Causes}

The precise etiology of PE is unknown, but involves multiple factors that differ between lifelong and acquired forms of the condition. Lifelong PE may be genetically determined, ${ }^{8-10}$ due to specific genetic polymorphisms in the dopamine transporter gene. ${ }^{11,12}$ Acquired PE is often attributed to endocrine, urological and neurological factors, or may be precipitated by psychological issues.

\section{Patient management}

Management includes non-pharmacological or pharmacological interventions or both. Psychotherapy-behavioural approaches attempt to reduce performance anxiety and promote communication between partners. In comparison, pharmacological interventions have a more immediate impact and are frequently the preferred first-line approach.

Two classes of pharmacological agents are used to treat PE: topical anesthetics and oral SSRIs. The concept of local control of PE with topical anesthetics was first reported in 1943..$^{13}$ Topical anesthetics, such as lidocaine, prilocaine or both, in cream, gel, ointment, or spray formulations, are applied prior to intercourse. ${ }^{14}$ They block neuronal voltagegated sodium channels to interrupt neural conduction, thereby reducing sensitivity to the glans and delaying ejaculation (Fig. 1). ${ }^{6,15}$ PSD502 (TEMPE), a topical eutectic-like mixture of prilocaine and lidocaine developed for the treatment of $P E$, is delivered using a metered-dose spray formulation containing 1,1,1,2-tetrafluoroethane (HFA-134a) as both the propellant and solvent. Upon actuation, a dose of $7.5 \mathrm{mg}$ lidocaine and $2.5 \mathrm{mg}$ prilocaine is deposited as a thin film on the glans. As the propellant rapidly vaporizes, the anesthetics are forced into a eutectic-like mixture; this slightly oily substance ensures good residency time on the penis. ${ }^{6}$ 
Common oral SSRIs include paroxetine, sertraline, fluoxetine and citalopram; these are widely used and meta-analysis (not controlled trials) on their efficacy have been conducted. These SSRIs block serotonin reuptake from synaptic clefts in serotonergic neurons thereby providing an inhibitory signal to the ejaculatory reflex. Daily administration of SSRIs improves ejaculation latency after 1 to 2 weeks of treatment. ${ }^{4}$ On-demand treatment about 4 hours before intercourse is significantly less effective than daily treatment. Dapoxetine, on the other hand, is a rapidacting, short-duration SSRI that was developed specifically for on-demand treatment of PE. ${ }^{5,16}$ It is administered orally 1 to 3 hours before intercourse. The tricyclic antidepressant clomipramine is also used for PE, but is not very effective. ${ }^{17}$

Guidelines are available for the pharmacological management of PE (Table 1). All guidelines recognize the importance of physicians' judgment and patients' preference and needs. ${ }^{1,2,4}$ Topical anesthetics are associated with fewer adverse events (AEs) compared with SSRIs, and are applied easily when need$\mathrm{ed}^{6}{ }^{6}$ this is relevant for those with infrequent sexual encounters. However, comparisons of topical versus oral agents must also address evidence of their efficacy in delaying ejaculation. Efficacy can be quantified by improvement from baseline in the intravaginal ejaculatory latency time (IELT), which measures the time from vaginal penetration to ejaculation. ${ }^{1}$ A couple's satisfaction can also be used to estimate efficacy.

\section{Key clinical trials}

\section{Topical}

\section{PSD502}

After the proof-of-concept study by Henry and colleagues, ${ }^{18}$ PSD502 was evaluated in 2 multicentre, double-blind, placebo-controlled trials involving men with lifelong PE (Table 2). ${ }^{15,19}$ Patients with IELT $\leq 1$ minute during a 4-week baseline period were randomized in a 2:1 ratio to use PSD502 or placebo for 3 months. Condoms were not permitted in the first study to evaluate the potential for partner contamination. Patients recorded the stopwatch-timed IELT together with efficacy and safety data in a diary. They were seen monthly for review and completion 2 validated patient-reported outcome questionnaires, the Index of Premature Ejaculation

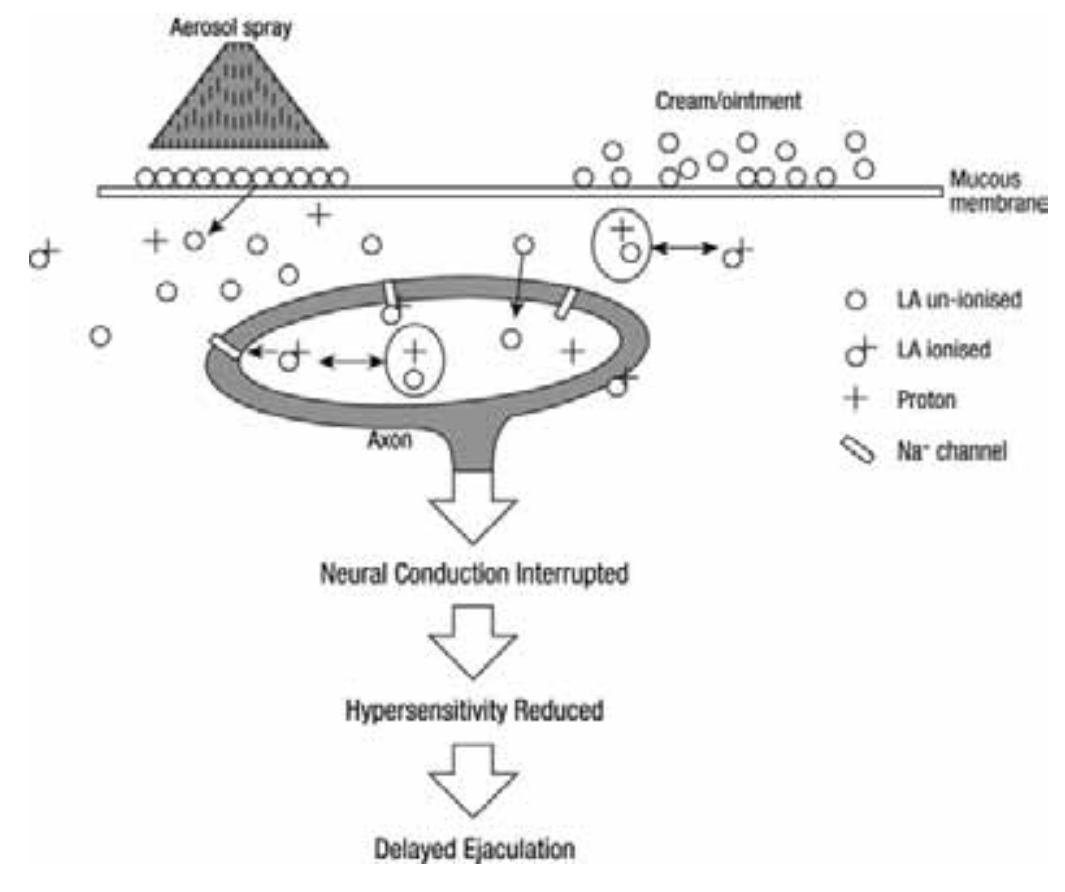

Fig. 1. Mode of action for topical local anesthetics (LAs) for treatment of premature ejaculation . Aerosol spray contains purely base (uncharged) forms of LAs; LA creams contain a mixture membranes. LAs produce localised reversible inhibition of nerve conduction by reducing the permeability of the neuronal membranes to sodium ions, the movement of which is necessary for the transmission of nerve impulses. Adapted from Henry et al. ${ }^{6}$

(IPE) and the Premature Ejaculation Profile (PEP). Partners recorded safety data in the diary and completed the partner PEP. Primary outcomes were changes in mean IELT from baseline during the 3-month study period and changes in the IPE domains of ejaculatory control and sexual satisfaction.

The first trial was conducted at 31 centres throughout Europe and included 290 men. PSD502 increased the geometric mean IELT from 0.6 minutes (range: $0-2.3$ ) during the baseline period to 3.8 minutes (range: $0.3-57.8$ ) over the 3-month treatment period (Fig. 2); mean IELT increased from 0.6 minutes (range: $0-3.3$ ) at baseline to 1.1 minutes (range: 0 -15.0) in the placebo cohort. The 6.3-fold increase in IELT with PSD502 was greater than the 1.7-fold increase with placebo $(p<0.001)$. PSD502 also improved the ejaculatory control, sexual satisfaction and distress domains of the IPE compared with placebo (all $p<0.001$ ). Patients using PSD502 were 12.8 times more likely to achieve a mean IELT $>2$ minutes than those in the placebo group $(p<0.001)$, and also were more likely to report a 1 -point or more increase on all 4 domains of the PEP $(p<0.001)$. Comparable improvements with PSD502 versus placebo were reported by the partners on the PEP $(p<0.001)$. At the end of the treatment period, $65.9 \%$ of patients in the PSD502 group rated the medication as "good" or "excellent" compared with $14.6 \%$ on placebo.

Comparable efficacy was reported in a second trial, conducted at 38 centres in Canada, the United States and 


\begin{tabular}{|c|c|c|c|}
\hline Therapy & AUA & EAU* & ICUSM \\
\hline \multicolumn{4}{|l|}{ NSSRI } \\
\hline Clomipramine (Anafranil) & $\begin{array}{l}25-50 \mathrm{mg} / \mathrm{day} \text {, or } 25 \mathrm{mg} \\
4-24 \mathrm{hr} \text { before intercourse }\end{array}$ & & $\begin{array}{c}12.5-50 \mathrm{mg} / \mathrm{day} \text {, or on demand } \\
4-6 \mathrm{hr} \text { before intercourse }\end{array}$ \\
\hline \multicolumn{4}{|l|}{ SSRI } \\
\hline Citalopram (Celexa) & & & 20-40 mg/day \\
\hline Dapoxetine (Priligy) & & $\begin{array}{c}30-60 \mathrm{mg} ; 1-2 \mathrm{hr} \text { before } \\
\text { intercourse }\end{array}$ & $\begin{array}{c}30-60 \mathrm{mg} ; \\
1-2 \mathrm{hr} \text { before intercourse }\end{array}$ \\
\hline Fluoxetine (Prozac, Sarafem) & 5-20 mg/day & $10-60 \mathrm{mg} / \mathrm{day}$ & $\begin{array}{c}20-40 \mathrm{mg} / \text { day, or on demand } \\
4-6 \mathrm{hr} \text { before intercourse }\end{array}$ \\
\hline Paroxetine (Paxil) & $\begin{array}{c}10-40 \mathrm{mg} / \text { day, or } \\
20 \mathrm{mg} \mathrm{3-4} \mathrm{hr} \text { before intercourse }\end{array}$ & $20-40 \mathrm{mg} / \mathrm{day}$ & $\begin{array}{c}10-40 \mathrm{mg} / \mathrm{day} \text {, or on demand } \\
4-6 \mathrm{hr} \text { before intercourse }\end{array}$ \\
\hline Sertraline (Zoloft) & $\begin{array}{c}25-200 \mathrm{mg} / \mathrm{day} \text {, or } \\
50 \mathrm{mg} 4-8 \mathrm{hr} \text { before intercourse }\end{array}$ & 25-200 mg/day & $\begin{array}{c}50-200 \mathrm{mg} / \text { day, or on demand } \\
4-6 \mathrm{hr} \text { before intercourse }\end{array}$ \\
\hline \multicolumn{4}{|l|}{ Topical therapies } \\
\hline $\begin{array}{l}\text { Lidocaine/prilocaine cream } \\
\text { (EMLA) }\end{array}$ & $\begin{array}{c}2.5 \% \text { cream; } \\
20-30 \text { min before intercourse }\end{array}$ & $\begin{array}{l}5 \% \text { cream; } 20-30 \text { min before } \\
\text { intercourse }\end{array}$ & Dose and timing not specified \\
\hline SS-cream & None stated & $0.2 \mathrm{~g}, 1 \mathrm{hr}$ before intercourse & None stated \\
\hline
\end{tabular}

Poland $(n=249) \cdot{ }^{19}$ PSD502 increased the geometric mean IELT from 0.56 minutes (range: 0.02-1.35) during baseline to 2.60 minutes (range: $0-40.37$ ) during the 3 -month treatment period, which was greater than the change from 0.53 minutes (range: 0.04-1.51) at baseline to 0.80 minutes (range: $0.23-8.05)$ in the placebo group $(p<0.0001)$. Again, PSD502 produced greater improvements in the IPE domains of ejaculatory control, sexual satisfaction and distress over placebo (all $p<0.0001$ ). Patients were 7.9 times more likely to achieve a mean IELT $>2$ minutes with PSD502 than with placebo $(p<0.0001)$, and more couples in the PSD502 group, compared with the placebo group, reported at least 1 -point increases in all 4 PEP domains (both $p<0.0001$ ). Patient satisfaction favoured PSD502, with $56.1 \%$ rating it as "good" or "excellent" compared with $8.9 \%$ of those on placebo.

PSD502 was well-tolerated. There were no systemic effects. Five patients $(2.6 \%)$ in the first study and 17 patients $(10.2 \%)$ in the second study had treatment-related AEs. ${ }^{15,19}$ Most common AEs were erectile dysfunction (1.0\%) and genital erythema $(1.0 \%)$ in the first study, and loss of erection $(5.4 \%)$ and hypoesthesia of penis $(3.0 \%)$ in the second. The incidence of treatment-related AEs reported by partners in the PSD502 group was $3.1 \%$ in the first study and $10.8 \%$ in the second study; the most common AEs were vulvovaginal burning sensation $(2.6 \%$ and $7.8 \%$, respectively) and discomfort $(0.5 \%$ and $1.2 \%$, respectively). Few treatment-related AEs were reported by couples in the placebo groups. ${ }^{15,19}$

These trials, as well as an earlier randomized controlled phase 2 trial, ${ }^{15}$ demonstrated that PSD502 applied 15 minutes before intercourse significantly improved all ejaculatory parameters, and was well-tolerated.

\section{Other topical preparations}

Other topical compounds have been investigated in small trials. ${ }^{20} \mathrm{~A}$ lidocaine-prilocaine $5 \%$ cream was evaluated in 40 patients with baseline IELT $<1$ minute. ${ }^{21}$ The participants were randomized to apply the cream or placebo 20,30 or 45 minutes before intercourse and using a condom. Mean IELT increased to 6.71 minutes in the group using the cream 20 minutes before intercourse compared with 1.0 minute for the control group. Six patients who applied the cream 30 minutes before intercourse and all patients applying the cream 45 minutes before had erection loss due to numbness. Application of the cream 20 minutes before intercourse was considered optimal. In another trial, 42 patients were randomized to use the lidocaine-prilocaine cream or an inert cream on each occasion of intercourse during a 30- to 60-day period. ${ }^{22}$ They were instructed to apply it to the glans penis up to $2 \mathrm{~cm}$ on the penile shaft for 10 to 20 minutes before intercourse, and to use a condom. The active cream increased mean IELT from 1.49 minutes at baseline to 8.45 minutes $(p<0.001)$; there was little change in IELT in the control group (1.67 to 1.95 minutes). Only 16 patients (72\%) using the active cream completed the study; 11 of them reported sexual satisfaction to be "great" or "excellent." Five men reported loss of penile sensation, delayed ejaculation and penile irritation; 1 partner had reduced vaginal sensitivity.

SS-cream is made from the extracts of 9 herbs. ${ }^{20}$ It is applied to the glans 1 hour before intercourse and washed off immediately before intercourse. In a controlled trial, the stopwatchmeasured IELT and sexual satisfaction of patient and partner were evaluated at baseline; the mean IELT was $1.37 \mathrm{~min}$ utes. Mean IELT increased to 10.92 minutes after use of the 


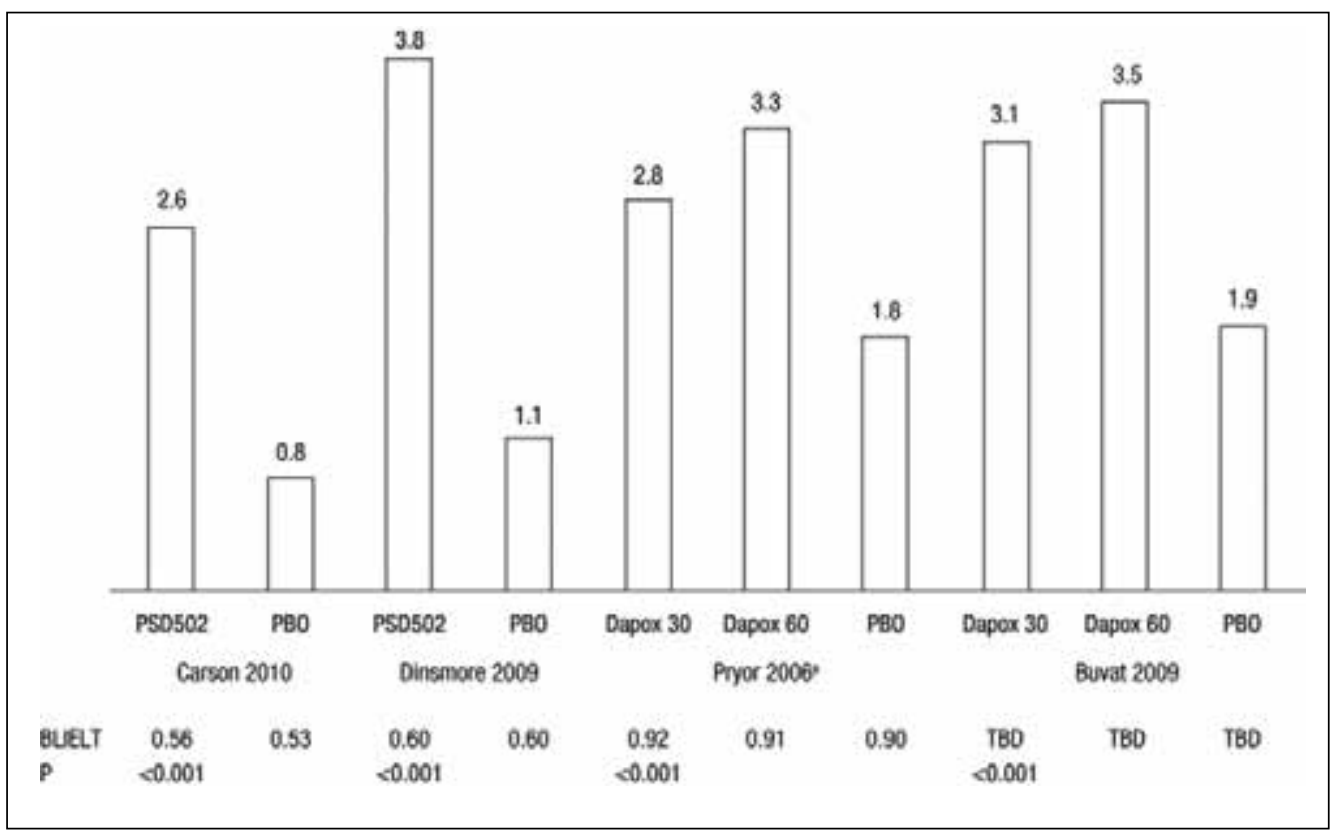

Fig. 2. Comparison of the effects of PSD502 and dapoxetine on intravaginal ejaculatory latency time (IELT) in patients with PE in phase 3 clinical trials. ${ }^{15,19,26,28}$ Geometric mean IELT shown for all studies, except Pryor et al ${ }^{26}$, which is presented as mean IELT. BL: baseline; Dapox: dapoxetine; IELT: intravaginal ejaculatory latency time; PBO: placebo; PE: premature ejaculation.

SS-cream compared with 2.45 minutes after use of the placebo cream $(p<0.001)$. Sexual satisfaction rates were higher after use of the SS-cream ( $82.2 \%$ vs. $19.8 \%)$. Mild local burning and pain were reported with the SS-cream after $18.5 \%$ of the applications, but no systemic AEs or effects on the partner were reported. ${ }^{23}$ No further studies have been reported since.

\section{Systemic}

\section{Conventional SSRIS}

Chronic daily treatment with SSRIs has been evaluated in numerous clinical trials using a variety of end points, and definitions of PE to qualify patients for enrolment. Study designs and treatment duration also varied across trials. ${ }^{24}$ Of these, 8 prospective, double-blind studies that used stopwatch-measured IELT were evaluated in a meta-analysis, including 4 placebo-controlled trials. The increase in IELT from baseline was $783 \%$ with paroxetine $20 \mathrm{mg} /$ day (4 groups), 313\% with sertraline $50 \mathrm{mg} /$ day (2 groups), and $295 \%$ with fluoxetine 20 or 40 mg/day (3 groups) compared with an increase of $47 \%$ with placebo (4 groups). Clomipramine 25 or $50 \mathrm{mg} /$ day was also evaluated in the meta-analysis, producing an IELT increase of $360 \%$ (2 groups). The increase in IELT with paroxetine was greater than with sertraline $(p<0.04)$ and greater than with clomipramine and fluoxetine. None of the studies included in the meta-analysis was a randomized controlled phase 3 trial. Another meta-analysis was conducted on trials evaluating on-demand therapy with SSRIs, but it was limited by greatly different methodology across trials. The results suggested that on-demand paroxetine and sertraline improved IELT, whereas on-demand clomipramine had only a mild effect. ${ }^{24}$

The efficacy of daily SSRIs is illustrated by the results of a double-blind trial comparing paroxetine $20 \mathrm{mg}$ /day, fluoxetine $20 \mathrm{mg} /$ day, sertraline $50 \mathrm{mg} /$ day and fluvoxamine 100 $\mathrm{mg}$ /day with placebo in a cohort of 60 men with lifelong PE and baseline IELT $\leq 1$ minute occurring in $>90 \%$ of sexual episodes. ${ }^{25}$ The geometric mean IELT increased gradually during treatment in the paroxetine (from 13 to 113 seconds), fluoxetine (from 18 to 135 seconds) and sertraline groups (from 19 to 84 seconds); marginal improvements were seen with placebo (from 15 to 22 seconds) and fluvoxamine (from 10 to 19 seconds). The increase from baseline in geometric mean IELT was 7.8-fold, 6.6-fold and 4.4-fold for paroxetine, fluoxetine, and sertraline, respectively; these were more than the 1.5-fold increase in the placebo group $(p<0.001$, $p<0.001$ and $p=0.017$, respectively). AEs were not reported, but 6 of the 48 patients $(12.5 \%)$ allocated to an SSRI did not complete the 6-week treatment period due to AEs. ${ }^{25}$ SSRIs cause a variety of mild and temporary AEs, including dryness of the mouth, nausea, diarrhea, insomnia, somnolence, tremor, decreased libido and increased sweating. ${ }^{4}$

\section{Dapoxetine}

Dapoxetine, an on-demand SSRI, was evaluated in 2 identically designed, 12-week, double-blind, parallel-group phase 


\begin{tabular}{|c|c|c|c|c|c|c|}
\hline \multirow[t]{2}{*}{ Reference } & \multirow[t]{2}{*}{ Treatment } & \multirow{2}{*}{$\begin{array}{c}\text { Route of } \\
\text { administration }\end{array}$} & \multirow[t]{2}{*}{ Patients } & \multicolumn{2}{|c|}{$\begin{array}{l}\text { Geometric mean } \\
\text { IELT }^{\mathrm{a}}(\mathrm{min})\end{array}$} & \multirow{2}{*}{$\begin{array}{l}\text { AEs reported }>5 \% \text { with active agent, and } \\
\text { more frequently than in placebo arm }\end{array}$} \\
\hline & & & & Baseline & End point & \\
\hline \multirow{2}{*}{ Carson 2010} & PSD502 $^{\mathrm{b}}$ & $\begin{array}{l}\text { Topical via metered- } \\
\text { dose spray; on }\end{array}$ & 167 & 0.56 & $2.6^{*}$ & \multirow{2}{*}{$\begin{array}{c}\text { Patient: loss or disappearance of erection } \\
\qquad(5.4 \%) ; \\
\text { Partner: vulvovaginal burning sensation } \\
(7.8 \%)\end{array}$} \\
\hline & Placebo & $\begin{array}{l}\text { demand; } 5 \text { min } \\
\text { before intercourse }\end{array}$ & 82 & 0.53 & 0.80 & \\
\hline \multirow{2}{*}{ Dinsmore 2009} & $\mathrm{PSD} 02^{\mathrm{b}}$ & $\begin{array}{l}\text { Topical via metered- } \\
\text { dose spray; on }\end{array}$ & 191 & 0.6 & $3.8^{\dagger}$ & \multirow{2}{*}{ None } \\
\hline & Placebo & $\begin{array}{l}\text { demand; } 5 \text { min } \\
\text { before intercourse }\end{array}$ & 99 & 0.6 & 1.1 & \\
\hline \multirow{3}{*}{ Pryor $2006^{c}$} & Dapoxetine $30 \mathrm{mg}$ & & 874 & 0.92 & $2.78^{*}$ & \multirow{3}{*}{$\begin{array}{c}\text { Nausea }(8.7 \%, 30 \mathrm{mg} ; 20.1 \%, 60 \mathrm{mg}), \\
\text { diarrhea }(6.8 \%, 60 \mathrm{mg}), \\
\text { headache }(5.9 \%, 30 \mathrm{mg} ; 6.8 \%, 60 \mathrm{mg}), \\
\text { dizziness }(6.2 \%, 60 \mathrm{mg})\end{array}$} \\
\hline & Dapoxetine $60 \mathrm{mg}$ & $\begin{array}{l}1-3 \mathrm{hr} \text { before } \\
\text { intercourse }\end{array}$ & 870 & 0.91 & $3.32 *$ & \\
\hline & Placebo & & 870 & 0.90 & 1.75 & \\
\hline \multirow{3}{*}{ Buvat 2009} & Dapoxetine $30 \mathrm{mg}$ & & 388 & 0.7 & $1.8^{\dagger}$ & \multirow{3}{*}{$\begin{array}{c}\text { Nausea }(16.5 \%, 30 \mathrm{mg} ; 30.6 \%, 60 \mathrm{mg}) \text {, } \\
\text { dizziness }(7.7 \%, 30 \mathrm{mg} ; 11.3 \%, 60 \mathrm{mg}) \\
\text { headache }(6.4 \%, 30 \mathrm{mg} ; 13.6 \%, 60 \mathrm{mg}) \\
\text { diarrhea }(11.3 \%, 60 \mathrm{mg}\end{array}$} \\
\hline & Dapoxetine $60 \mathrm{mg}$ & $\begin{array}{l}\text { Oral; on demand; } \\
\text { 1-3 hr before } \\
\text { intercourse }\end{array}$ & 389 & 0.7 & $2.3^{\dagger}$ & \\
\hline & Placebo & & 385 & 0.7 & 1.1 & \\
\hline
\end{tabular}

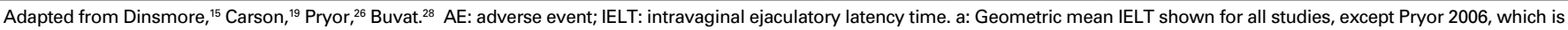
presented as mean IELT; b: Three actuations of metered-dose spray; each actuation delivers lidocaine $7.5 \mathrm{mg}$ and prilocaine $2.5 \mathrm{mg}$; : This was a pooled analysis of 2 phase 3 , double-blind, placebo-controlled trials. ${ }^{*} p<0.0001 ;+p<0.001$.

3 trials conducted at a total of 121 U.S sites (Table 2). ${ }^{26}$ Men with an IELT $\leq 2$ minutes during a 2-week baseline period were randomized to dapoxetine $30 \mathrm{mg}, 60 \mathrm{mg}$, or placebo to be taken 1 to 3 hours before intercourse. The primary efficacy end point was the stopwatch-reported IELT at the final visit. The 2 studies included 2614 patients; of these, 1958 (75\%) completed the 12-week trial. The mean IELT increased in all groups, from 0.92 to 2.78 minutes with dapoxetine $30 \mathrm{mg}, 0.91$ to 3.32 minutes with dapoxetine $60 \mathrm{mg}$, and 0.90 to 1.75 minutes for placebo $(p<0.0001) .{ }^{26}$ Both dapoxetine doses produced greater IELT increases compared with placebo in the subgroups with baseline IELT $\leq 1$ minute and $>1$ to $\leq 2$ minutes $(p<0.0001)$. Both doses allowed more patients to achieve an IELT $\geq 3$ minutes $(29 \%$ and $34 \%$ vs. $14 \% ; p<0.0001)$ and improved perception of ejaculatory control and sexual satisfaction $(p<0.0001) .{ }^{27}$

Another 24-week phase 3 trial was conducted in 22 countries to compare on-demand dapoxetine $30 \mathrm{mg}$ and $60 \mathrm{mg}$ versus placebo in 1162 participants. They had IELTs $\leq 2$ minutes in at least $75 \%$ of sexual events during the 4-week baseline period. Patients took the drug 1 to 3 hours before anticipated intercourse, and the primary end point was the stopwatch-measured IELT. ${ }^{28}$ Dapoxetine increased IELT after the first dose and at all subsequent time points. The mean IELT increased from 0.9 minutes at baseline to $1.9 \mathrm{~min}$ utes with placebo; 3.1 minutes with dapoxetine $30 \mathrm{mg}$, and 3.5 minutes with dapoxetine $60 \mathrm{mg}(p<0.001)$. Dapoxetine also improved PEP domains of sexual satisfaction and distress and the Clinical Global Impression of Change compared with placebo.
Dapoxetine increased AEs in a dose-related manner compared with placebo. In the first 2 phase 3 trials, the most common AEs with the 30-mg and 60-mg doses versus placebo were nausea $(8.7 \%$ and $20.1 \%$ vs. $1.9 \%)$, diarrhea $(3.9 \%$ and $6.8 \%$ vs. $1.4 \%)$, headache $(5.9 \%$ and $6.8 \%$ vs. $4.0 \%)$ and dizziness $(3.0 \%$ and $6.2 \%$ vs. $0.8 \%) .{ }^{26,29}$ Erectile dysfunction was reported more often in the dapoxetine arms $(2.9 \%$ and $3.8 \%$ vs. $1.5 \%$ ). In a more recent phase 3 trial, the most common AEs were nausea (16.5\% and $30.6 \%$ vs. $2.9 \%$ ), dizziness $(7.7 \%$ and $13.4 \%$ vs. $2.6 \%)$, diarrhea $(3.9 \%$ and $11.3 \%$ vs. $1.6 \%)$ and headache $(6.4 \%$ and $13.6 \%$ vs. $8.3 \%)$. The risk of suicidal ideation in depressed patients, particularly adolescents, treated with SSRIs has been a controversial issue. ${ }^{30}$ Although SSRIs are more likely to be prescribed to patients at risk of suicide, there seems to be a higher rate of suicides among patients so treated. However, other studies suggest this is uncommon and the risk disappears after 30 days of therapy. ${ }^{31}$ None of the studies included dapoxetine and a recent review of dapoxetine trials for PE in adults did not find "anxiety, akhathisia, suicidality or changes in mood." 32

\section{Limitations in comparing efficacy among treatments}

Randomized, phase 3 clinical trials showed that on-demand treatment with topical PSD502 or oral dapoxetine is more effective than placebo at improving IELT in patients with PE. ${ }^{15,19,26,28,29}$ Conventional SSRIs have not been evaluated in phase 3 trials, but numerous smaller phase 2 studies indicated that daily treatment with paroxetine, fluoxetine and sertraline was effective, while on-demand treatment was 
marginally effective. ${ }^{24}$ Current evidence precludes comparative analysis of efficacy parameters of these drugs across clinical trials because they lack consistency in the definition of $\mathrm{PE}$, entry criteria for patient enrolment, statistical analysis of IELT and psychometric instruments used in the trials. ${ }^{2}$ Moreover, it is difficult to quantify the amount of stimulation experienced by patients, in that the IELT is a multifactorial function. The lack of a consistent stimulus, which reflects partner variables, the type of sexual activity and foreplay, preferences and socio-cultural differences, limits comparisons across trials.

\section{Conclusion}

Several factors are important in considering pharmacotherapy for PE: improvement of IELT and patient-reported outcomes, safety and tolerability profile, and route and schedule of administration. The choice depends on the individual's needs, preferences and medical history. Evidence demonstrated that PSD502, dapoxetine and other SSRIs significantly improve the symptoms of PE. Systemic use of SSRIs carries its own inherent risks associated with this class of drug. PSD502 allows for topical on-demand treatment and is not associated with systemic AEs. Topical therapy should be considered first-line pharmacological treatment.

Competing interests: None declared.

This paper has been peer-reviewed.

\section{References}

1. Rowland DL, McMahon C, Abdo C, et al. Disorders of orgasm and ejaculation in men. J Sex Med 2010;7:1668-86. http://dx.doi.org/10.1111/j.1743-6109.2010.01782.x

2. Montague DK, Jarow J, Broderick $G$. Erectile dysfunction guideline update panel. AUA guideline on the pharmacologic management of premature ejaculation. J Urol 2004;172:290-4. http://dx.doi. org/10.1097/01.ju.0000132159.61156.ea

3. McMahon $C G$, Althof $S$, Waldinger MD. An evidence-based definition of lifelong premature ejaculation: report of the International Society for Sexual Medicine Ad Hoc Committee for the definition of premature ejaculation. BJU Int 2008;102:338-50. http://dx.doi.org/10.1111/i.1464-410X.2008.07755.x

4. Hatzimouratidis K, Amar E, Eardley I, et al. Guidelines on male sexual dysfunction: erectile dysfunction and premature ejaculation. Eur Urol 2010;57:804-14. http://dx.doi.org/10.1016/i.eururo.2010.02.020

5. Jannini EA, Porst H. A practical approach to premature ejaculation. J Sex Med 2011:8 (suppl 4):301-3. http://dx.doi.org/10.1111/i.1743-6109.2011.02456.x

6. Henry R, Morales A, Wyllie M. Topical eutectic-like mixture for premature ejaculation. Expert Opin 2008:5:251-61.

7. Priligy (dapoxetine) receives first regulatory approvals for the treatment of premature ejaculation (PE) in Finland and Sweden. Medical News Today. February 17, 2009. http://medicalnewstoday.com/ articles/139293.php (Accessed September 13, 2012).

8. Waldinger MD, Rietschel $M$, Nothern NM. Familial occurrence of primary premature ejaculation. Psychiatr Genet 1998;8:37-40. http://dx.doi.org/10.1097/00041444-199800810-00007

9. Buvat J. Pathophysiology of premature ejaculation. J Sex Med 2011;8(suppl 4):316-27. http://dx.doi. org/10.1111/j.1743-6109.2011.02384.x

10. Jern $P$, Santilia $P$, Johansson $A$, et al. Evidence for a genetic etiology to ejaculatory dysfunction. Int J Impot Res 2009;21:62-7. http://dx.doi.org/10.1038/iiir.2008.61
11. Santtila P, Jern P, Westberg L. The dopamine transporter gene (DATI) polymorphism is associated with premature ejaculation. J Sex Med 2010;7:1538-46. http://dx.doi.org/10.1111/i.17436109.2009.01696.x

12. Janssen PK, Baker SC, Rethelyi J, et al. Serotonin transporter promoter region (5-HTTLPR) polymorphism is associated with intravaginal ejaculation latency time in Dutch men with lifelong premature ejaculation. J Sex Med 2009;6:276-84. http://dx.doi.org/10.1111/i.1743-6109.2008.01033.x

13. Schapiro B. Premature ejaculation: a review of 1130 cases. J Urol 1943;50:374-7.

14. Porst H. An overview of pharmacotherapy in premature ejaculation. J Sex Med 201 1;8(suppl 4):335-41. http://dx.doi.org/10.1111/i.1743-6109.2011.02451.x

15. Dinsmore W, Wyllie M. PSD502 improves ejaculatory latency, control and sexual satisfaction when applied topically 5 min before intercourse in men with premature ejaculation: results of a phase III, multicentre, double-blind, placebo-controlled study. BJU Int 2009;103:940-9. http://dx.doi.org/10.1111/j.1464410X.2009.08456.X

16. Kendirci M, Salem E, Hellstrom WJG. Dapoxetine, a novel selective serotonin transport inhibitor for the treatment of premature ejaculation. Ther Clin Risk Manag 2007;3:277-89. http://dx.doi.org/10.2147/ term.2007.3.2.277

17. Patel K, Hellstrom WJ. Central regulation of ejaculation and the therapeutic role of serotonergic agents in premature ejaculation. Curr Opin Investig Drugs 2009;10:681-90.

18. Henry R, Morales A. Topical lidocaine-prilocaine spray for the treatment of premature ejaculation: a proof of concept study. Int J Impot Res 2003;15:277-81. http://dx.doi.org/10.1038/si.jiir.3901011

19. Carson C, Wyllie M. Improved ejaculatory latency, control, and sexual satisfaction when PSD502 is applied topically in men with premature ejaculation: Results of a Phase III, double-blind, placebo-controlled study. J Sex Med 2010;7:3179-89. http://dx.doi.org/10.1111/i.1743-6109.2010.01913.x

20. Morales A, Barada J, Wyllie MG. A review of the current status of topical treatments for premature ejaculation. BJU Int 2007;100:493-501. http://dx.doi.org/10.1111/j.1464-410X.2007.07051.x

21. Atikeler MK, Gecit I, Senol FA. Optimun usage of prilocaine-lidocaine cream in premature ejaculation. Andrologia 2002;34:356-9. http://dx.doi.org/10.1046/i.1439-0272.2002.00511.x

22. Busato W, Galindo CC. Topical anesthetic use for treating premature ejaculation: a double-blind, randomized, placebo-controlled study. BJU Int 2004;93:1018-21. http://dx.doi.org/10.1111/j.1464410X.2003.04773.x

23. Choi HK, Jung GW, Moon KH, et al. Clinical study of SS-cream in patients with lifelong premature ejaculation. Urology 2000;55:257-61. http://dx.doi.org/10.1016/S0090-4295(99)00415-X

24. Waldinger MD, Zwinderman AH, Schweitzer DH. Relevance of methodological design for the interpretation of efficacy of drug treatment of premature ejaculation: a systematic review and meta-analysis. Int I Impot Res 2004;16:369-81. http://dx.doi.org/10.1038/si.jii. 3901172

25. Waldinger MD, Hengeveld W, Zwinderman AH. Effect of SSRI antidepressants on ejaculation: a doubleblind, randomized, placebo-controlled study with fluoxetine, fluvoxamine, paroxetine, and sertraline. J Clin Psychopharmacol 1998;18:274-81. http://dx.doi.org/10.1097/00004714-199808000-00004

26. Pryor JL, Althof SE, Steidle C. Efficacy and tolerability of dapoxetine in the treatment of premature ejaculation: an integrated analysis of two double-blind, randomised controlled trials. Lancet 2006;368:929-37. http://dx.doi.org/10.1016/S0140-6736(06)69373-2

27. Shabsigh R, Patrick DL, Rowland DL. Perceived control over ejaculation is central to treatment benefit in men with premature ejaculation: results from phase III trials with dapoxetine. BJU Int 2008;102:824-8. http://dx.doi.org/10.1111/i.1464-410X.2008.07845.x

28. Buvat J, Tesdaye $F$, Rothman $M$, et al. Dapoxetine for the treatment of premature ejaculation: results from a randomized, double-blind, placebo-controlled phase 3 trial in 22 countries. Eur Urol 2009;55:957-67. http://dx.doi.org/10.1016/i.eururo.2009.01.025

29. McMahon C, Kim SW, Park NC, et al. Treatment of premature ejaculation in the Asia-Pacific region: results from a phase III double-blind, parallel-group study of dapoxetine. J Sex Med 2010;7:256-68. http:// dx.doi.org/10.1111/i.1743-6109.2009.01560.x

30. Gunnel $\mathrm{D}$, Middleton $\mathrm{N}$, Whitley $\mathrm{E}$, et al. Why are suicide rates rising in young men but falling in the elderly? A time-series analysis of trends in England and Wales. Soc Sci Med 2003;57:595-611.

31. Hall WD. How have had the SSRI antidepressants affected suicide risk? Lancet 2006;367:1959-62. http://dx.doi.org/10.1016/S0140-6736(06)68860-0

32. McMahon, CG, Althof SE, Kaufman JM, et al. Efficacy and safety of dapoxetine for the treatment of premature ejaculation: Integrated analysis of results from five phase 3 trials. I Sex Med 201 1;8:524-39. http://dx.doi.org/10.1111/i.1743-6109.2010.02097.x

Correspondence: Dr. Alvaro Morales, 59 Lakeshore Blvd. Kingston, ON K7M 6R4; fax: 613-3899275; moralesa@queensu.ca 